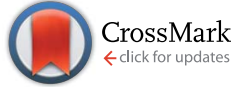

Cite this: RSC Adv., 2015, 5, 88070

Received 13th August 2015

Accepted 9th October 2015

DOI: $10.1039 / c 5 \mathrm{ra16337d}$

www.rsc.org/advances

\section{Two step and one step preparation of porous nanocomposite cellulose membranes doped with $\mathrm{TiO}_{2} \dagger$}

\begin{abstract}
Alexandra Wittmar, ${ }^{\star a b}$ Dimitri Vorat ${ }^{a}$ and Mathias Ulbricht ${ }^{\star a b}$
Cellulose- $-\mathrm{TiO}_{2}$ nanocomposites have been successfully prepared by non-solvent induced phase separation from cellulose acetate solutions in classical organic solvents followed by deacetylation ("regeneration"). The cellulose deacetylation has been performed either sequentially, i.e. after the completion of the phase separation process, or simultaneously, i.e. during the phase separation process. Commercially available titania nanoparticles from gas phase synthesis processes have been used and processed as a dispersion in the respective polymer solutions. The resulting nanocomposites have been characterized by means of scanning electron microscopy (SEM) and Fourier transform infrared (FT-IR) spectroscopy. Special attention has been given to the complex relation between the conditions of the deacetylation process, the structure of the resulting $\mathrm{TiO}_{2}$ doped cellulose membranes and their corresponding catalytic activities. Two catalytic activity tests, based on the photocatalytic degradation of model organic dyes under UV irradiation, have been used for the functional characterization of the $\mathrm{TiO}_{2}$ doped nanocomposites. The performed experiments demonstrated the successful photocatalyst immobilization in porous cellulose acetate together with good catalytic activity of this nanocomposite intermediate. By simply varying the conditions of the cellulose deacetylation, nanocomposite cellulose membranes with different structures and properties have been obtained. However after the regeneration of cellulose a partial decrease of the catalytic activity was observed.
\end{abstract}

\section{Introduction}

Cellulose is one of the most widely available natural polymers and together with its derivatives has already many established areas of applicability such as in paper manufacturing, ${ }^{1}$ artificial fibers and textiles, ${ }^{2,3}$ membranes for water purification ${ }^{4,5}$ and/or biomedical analyses and therapies. ${ }^{6,7}$ Cellulose-based materials with new functionalities have continuously attracted the interest of chemistry researchers, following the current trends to utilize renewable and environmentally friendly,

${ }^{a}$ Lehrstuhl für Technische Chemie II, Universität Duisburg-Essen, 45141 Essen, Germany. E-mail: alexandra.wittmar@uni-due.de; mathias.ulbricht@uni-due.de; Fax: +492011833147

${ }^{b}$ CENIDE - Center for Nanointegration Duisburg-Essen, NETZ NanoEnergieTechnikZentrum, 47057 Duisburg, Germany

$\uparrow$ Electronic supplementary information (ESI) available: Particle size distribution (DLS) of different $\mathrm{TiO}_{2}$ nanoparticles in dimethylformamide; particle size distribution (DLS) of $\mathrm{TiO}_{2} \mathrm{P} 90$ in different solvents; particle size distribution (DLS) of $\mathrm{TiO}_{2} \mathrm{P90}$ in different concentrations in dimethylformamide; SEM images of cellulose acetate- $\mathrm{TiO}_{2}$ nanocomposites with different types of $\mathrm{TiO}_{2}$; SEM images of the surfaces of cellulose acetate- $\mathrm{TiO}_{2}$ membranes prepared from acetone and dimethylformamide polymer solutions; water contact angles of cellulose acetate- $\mathrm{TiO}_{2}$ membranes prepared from polymer solutions in acetone and dimethylformamide; FT-IR spectra of different cellulose acetate- $\mathrm{TiO}_{2}$ membranes before, during and after the deacetylation; additional results regarding the catalytic activity of nanocomposites. See DOI: 10.1039/c5ra16337d abundantly available and biodegradable materials in all fields of application. Doping cellulose and derivatives with inorganic nanoparticles leads to the formation of inorganic-organic hybrid nanocomposites which by the synergistic combination of the components' characteristics can exhibit additional functionalities as well as superior thermal, mechanical, electrical and optical properties. This way the area of applicability of the cellulose based materials can be widely expanded. For example, doping cellulose with silica or montmorillonite, nanocomposites with improved thermal and mechanical stability have been obtained, ${ }^{\mathbf{8} 9}$ and by doping cellulose with $\mathrm{SnO}_{2}$ materials for chemical, humidity and biomarker sensing have been produced. ${ }^{\mathbf{1 0}}$ Ferromagnetic nanoparticles like $\mathrm{MnFe}_{2} \mathrm{O}_{4}$ confer cellulose water repellent and superparamagnetic properties as well as magnetic responsivity. ${ }^{\mathbf{1 1}}$ $\mathrm{ZnO}$ and $\mathrm{Ag}^{+}$confer cellulose biocompatibility and antibacterial activity ${ }^{\mathbf{1 2 , 1 3}}$ and $\mathrm{TiO}_{2}$ doping provides antibacterial ${ }^{\mathbf{1 4}}$ and catalytic activity. ${ }^{15}$

One of the materials with a huge role in nanoscience and nanotechnology is $\mathrm{TiO}_{2}$. Among its main areas of applications worth mentioning are catalysis, ${ }^{\mathbf{1 6}}$ solar cells, ${ }^{17}$ pigments, ${ }^{18}$ corrosion protection ${ }^{19}$ or optical coatings. ${ }^{20} \mathrm{TiO}_{2}$ is one of the mostly used photocatalysts for the decomposition of organic and inorganic contaminants like $\mathrm{Cr}(\mathrm{vI})$ in wastewater due to its superior properties: high chemical stability, low toxicity and low 
cost. ${ }^{21,22}$ Widespread are three polymorphic forms of $\mathrm{TiO}_{2}$ : anatase, rutile and brookite, and some commercial powders usually consist of mixtures of anatase and rutile. The bandgap of rutile is $\sim 3.0 \mathrm{eV}$ and that of anatase is $\sim 3.2 \mathrm{eV} .{ }^{23}$ Generally it is considered that in pure form anatase exhibits superior photocatalytic activity. ${ }^{24}$ In depth studies have demonstrated that phase mixtures of different $\mathrm{TiO}_{2}$ polymorphs have increased photocatalytic activity when compared with pure phases. ${ }^{25}$

A wide range of cellulose-based nanocomposites doped with $\mathrm{TiO}_{2}$ have been prepared by different processes and have found different applications like: nanohybrid membranes with improved porosity, stability and separation performance; ${ }^{26}$ selfcleaning materials and purification filters with predefined hydrophilicity; ${ }^{27}$ nanocomposites with high bactericidal activity $^{28,29}$ and nanocomposites with photocatalytic activity. ${ }^{30-32}$ In one of the most recent applications, the $\mathrm{TiO}_{2}$ doped cellulose materials were used for water purification by photocatalytic reactions. $^{33}$

Cellulose is insoluble in water and in most of the conventional organic solvents and it decomposes before reaching the melting temperature; therefore processing of cellulose in unmodified form is rather difficult. The main reason for cellulose insolubility is connected with its high crystalline content which is strongly connected to the dense chain packing due to intra- and intermolecular hydrogen bonding. The traditional methods for the preparation of "regenerated" cellulose materials include cellulose dissolution in aqueous xanthate solutions, or solutions of cellulose in lithium chloride-dimethylacetamide mixtures, sodium hydroxide-thiourea aqueous solutions or tetraalkylammonium chloride solutions in organic solvents. More recent studies were dedicated to the dissolution of cellulose in a new class of non-derivatizing solvents-room temperature ionic liquids. ${ }^{34}$

Some of the above mentioned processes are hazardous to the environment; some involve relatively expensive solvents or imply difficult processing due to high viscosity of the cellulose solutions. In contrast to cellulose, cellulose acetate has less hydrogen bonds and a lower crystallinity; this makes it easily soluble in a wide range of organic solvents like acetone, dimethylformamide (DMF), dimethylsulfoxide (DMSO) etc.

One of the most widely spread methods for porous films and membranes preparation is the phase separation from a polymer solution either by thermally induced, vapor induced or by non-solvent immersion precipitation processes. In non-solvent induced phase separation, a polymer solution which may contain other additives is cast on a flat substrate as a thin film. Subsequently the film is immersed in a coagulation bath which contains the nonsolvent, may also contain other additives and is highly miscible with the polymer solvent. The final pore morphology of the formed membrane depends on the exchange between the solvent and the non-solvent, influenced by the composition of the polymer solution and the coagulation bath, by the polymer concentration in solution, by the solvent and nonsolvent volatility, etc. ${ }^{3,36}$ Very recently a research group from Malaysia has reported the successful preparation by non-solvent induced phase separation of cellulose membranes loaded with $\mathrm{N}$-doped $\mathrm{TiO}_{2}$ from a cellulose solution in an ionic liquid. The obtained membranes very efficiently degraded organic dye methylene blue under UV and visible irradiation. ${ }^{37,38}$ The main downside of the cellulose membrane formation from solutions in ionic liquids is given by the high viscosity of the polymer solution which makes the control of pore formation difficult. ${ }^{39}$ In one of our previous works we reported on two alternative routes which facilitate the preparation of catalytically active cellulose membranes using commercial $\mathrm{TiO}_{2}$ nanoparticles as active functional material: one starting with cellulose solutions in ionic liquids and the second starting with cellulose acetate solutions in conventional solvents. ${ }^{39}$ In the present paper we analyze in depth the possibilities to prepare $\mathrm{TiO}_{2}$ doped porous cellulose membranes, starting with $\mathrm{TiO}_{2}$ doped cellulose acetate solutions in conventional solvents which are transformed in porous nanocomposites by phase separation process. The cellulose is simply regenerated by alkaline treatment of the cellulose acetate intermediate, either directly during the phase separation process or in a subsequent separate step. The proposed processes combine the advantage of cellulose acetates' facile solubilisation in organic solvents with the use of well dispersed cheap commercially available catalytically active $\mathrm{TiO}_{2}$ nanoparticles and the facile design of porous membrane structure by the choice of phase separation conditions. The intermediate cellulose acetate nanocomposite membranes possess catalytic activity and may find direct applications in water purification processes or self-cleaning surfaces. A partial loss of catalytic activity after the deacetylation process has been observed; therefore future studies concerning the optimal deacetylation conditions or the post-synthesis reactivation of the catalyst are necessary.

\section{Materials and methods}

\subsection{Materials}

Cellulose acetate (CA) with a molecular weight $M_{\mathrm{n}} \sim 30000 \mathrm{~g}$ $\mathrm{mol}^{-1}$ and an acetyl content of $39.8 \mathrm{wt} \%$, as given by the provider, was supplied by Sigma-Aldrich. Cellulose acetate solutions were prepared in acetone (p.a.) and dimethylformamide (DMF; p.a.), both supplied by VWR International. Titan dioxide nanoparticles $\mathrm{TiO}_{2}$ Aeroxide $\mathrm{P} 90$ were kindly offered by Evonik Industries, $\mathrm{TiO}_{2}$ Hombikat 8630 and $\mathrm{TiO}_{2}$ Hombikat 8602 were kindly offered by Sachtleben Chemie GmbH. The dyes used for the catalytic activity tests were methylene blue (hydrate; $\geq 95 \%$ ) from Fluka and rhodamine B (96\%) from Alfa Aesar. During the cellulose regeneration process $\mathrm{KOH}$ (p.a.), HCl 0.1 M (standard solution) and ethanol (96\%, Ph. Eur.) from VWR International were used.

\subsection{Preparation of cellulose based membranes}

The $\mathrm{TiO}_{2}$ dispersions in acetone and DMF were prepared at the desired concentrations $(10,15$ and $20 \mathrm{wt} \%$ with respect to the polymer) by treatment with a Bandelin Sonoplus Generator 
GM 2200 ultrasound homogenisator. The solvents and the corresponding amount of nanoparticle powder were introduced in a glass vial and then homogenized for $2 \times 5$ min with amplitude of $30 \%$. Between the sonication intervals a pause of 5 min was necessary in order to avoid the overheating of the dispersion.

For the preparation of the polymer solutions (with or without nanoparticles) the solvent or nanoparticle dispersions were mixed with the desired amount of polymer ( $16 \mathrm{wt} \%$ with respect to the solvent) and homogenized in a mortar, and then the samples were stirred at room temperature until complete polymer dissolution.

The polymer films were casted on glass substrates with the help of a motorized film applicator (model AB3400 from TQC), using a casting knife with gap width of $300 \mu \mathrm{m}$ and a speed of $20 \mathrm{~mm} \mathrm{~min}^{-1}$. The glass supported polymer films were immediately immersed (average residence time after casting ca. $30 \mathrm{~s}$ ) in the coagulation bath consisting of distilled water at room temperature and were left there for $c a$. $24 \mathrm{~h}$ in order to allow completion of phase separation. When the membrane deacetylation was performed simultaneously with the membrane precipitation, the polymer film was immersed in a $\mathrm{KOH}$ solution in water or in water/EtOH mixture. When the deacetylation was performed post preparation, the cellulose acetate wet membrane was transferred in a $\mathrm{KOH}$ water bath of known concentration. Different $\mathrm{KOH}$ concentrations in the coagulation bath $(0.05 \mathrm{~N}, 0.1 \mathrm{~N}, 0.2 \mathrm{~N}$, $0.25 \mathrm{~N}$ and $0.5 \mathrm{~N}$ ) and different regeneration time intervals (between $1 \mathrm{~h}$ and $24 \mathrm{~h}$ ) have been studied. Subsequently, the membranes were washed with fresh distilled water and dried in air at room temperature.

\subsection{Characterization methods}

The agglomerate size in dispersion, $d_{\text {DLS }}$, was determined by dynamic light scattering (DLS) method using a Particle Metrix Stabisizer heterodyne backscattering equipment at a laser wavelength of $500 \mathrm{~nm}$ and a laser power of $5 \mathrm{~mW}$. Each sample was measured three times over a period of $60 \mathrm{~s}$ for each run and the result is the average of the three measurements. The DLS data are presented as distribution by number, but the distribution by intensity was also recorded for a better interpretation of the results.

Scanning electron micrographs of the porous membranes at different magnifications were taken with a FEI ESEM Quanta 400 FEG instrument. For the cross section measurements the samples were broken in liquid nitrogen. The samples were sputtered with $\mathrm{Au} / \mathrm{Pd}(80 / 20)$ at $0.1 \mathrm{mbar}$ and $30 \mathrm{~mA}$ for $30 \mathrm{~s}$ until a layer of 2-3 nm was obtained.

The results of the deacetylation process were evaluated with help of FT-IR ATR spectroscopy using a Varian 3100 Excalibur series spectrometer with an angle of incidence of $45^{\circ}$ and a diamond crystal. The $600-4000 \mathrm{~cm}^{-1}$ spectral range was measured with at an average of 32 scans per sample and with a resolution of $4 \mathrm{~cm}^{-1}$.

The catalytic activity of the nanoparticle doped cellulosebased nanocomposites has been evaluated in the photodegradation of organic dyes like methylene blue or rhodamine B in two tests:

Test 1. Membrane pieces of $1 \mathrm{~cm}^{2}$ were impregnated with aqueous solutions of organic dyes $\left(2 \times 10^{-5} \mathrm{M}\right)$ : each membrane piece was immersed in $30 \mathrm{~mL}$ of dye solution and was maintained there in dark conditions for $30 \mathrm{~min}$. The membrane pieces after removal from dye solution were placed in an open Petri dish and exposed to the UV radiation (365 $\mathrm{nm}$ ) in a TLC CN-15 viewing cabinet from Vilber Lourmat $\mathrm{GmbH}$ equipped with $2 \times 15 \mathrm{~W}$ lamps and yielding an UV intensity at location of the sample of $1050 \mu \mathrm{W} \mathrm{cm}{ }^{-2}$. Samples were also exposed to sunlight in sunny days in May 2015. Digital pictures were taken before UV exposure and after specific periods of time. In the recyclability test the procedure was repeated several times. For this test the preferred dye was methylene blue $(5 \times$ $10^{-5} \mathrm{~mol} \mathrm{~L}^{-1}$ in water) because it offers better contrast for digital photographic pictures.

Test 2. In order to assess the photodegradation efficiency in a heterogeneously catalyzed water treatment process, pieces of wet membrane $\left(1 \mathrm{~cm}^{2}\right)$ or milled dried nanocomposite, containing $0.01 \mathrm{~g} \mathrm{TiO}_{2}$, were inserted in $30 \mathrm{~mL}$ of aqueous dye solution $\left(5 \times 10^{-5} \mathrm{M}\right)$. The mixtures were first stirred in dark conditions until the adsorption-desorption equilibrium had been reached, then the samples were exposed for a certain amount of time to UV light (365 nm) under same conditions as in Test 1 . Small samples of dye solution were taken periodically by a syringe and the catalyst was filtered off with a $0.2 \mu \mathrm{m}$ cellulose acetate microfiltration membrane (Sartorius). The variation of dye concentration with irradiation time was followed by UV-Vis spectroscopy using an UviLine 9400 Spectrometer from Schott Instruments. The measurements were performed in the $400-800 \mathrm{~nm}$ spectral range with a resolution of $1 \mathrm{~nm}$. For comparison purposes, the photo-degradation of 30 $\mathrm{mL}$ aqueous dye solution $\left(5 \times 10^{-5} \mathrm{M}\right)$ with $0.01 \mathrm{~g}$ pure $\mathrm{TiO}_{2} \mathrm{P90}$ powder was analyzed in analogous manner (Test 2). The change of dye concentration as function of irradiation time for $30 \mathrm{~mL}$ aqueous solution of rhodamine $\mathrm{B}\left(5 \times 10^{-5} \mathrm{M}\right)$ in the absence of the catalysts was also recorded.

\section{Results and discussion}

The $\mathrm{TiO}_{2}$ P90 nanoparticles are preponderantly constituted from anatase phase, i.e. ca. $97 \%$ (primary particle size for anatase is $10-14 \mathrm{~nm}$ ) and only ca. $3 \%$ rutile (primary particle size for rutile is $12-17 \mathrm{~nm}$ ) content. These particle size distributions calculated from the XRD patterns are in good agreement with the observations in transmission electron micrographs. ${ }^{32}$ According to producer specifications, the $\mathrm{TiO}_{2}$ Hombikat 8630 is constituted from a fine particulate anatase with $5 \% \mathrm{WO}_{3}$ and the $\mathrm{TiO}_{2}$ Hombikat 8602 is a fine particulate titanium oxide hydrate (primary particles size 5-10 $\mathrm{nm}$ ) with anatase structure and very large specific surface area $>250 \mathrm{~m}^{2} \mathrm{~g}^{-1}$.

The agglomeration of the $\mathrm{TiO}_{2}$ nanoparticles in the solvents of interest was analyzed by dynamic light scattering DLS (see ESI, Fig. SI-1†). The three types of $\mathrm{TiO}_{2}$ disperse differently in $\mathrm{DMF}$, the average agglomerate size is increasing in the following 
Rhodamine $B\left(5 \times 10^{-5} \mathrm{~mol} / /\right.$ in water $)$ degradation by UV excitation at $365 \mathrm{~nm}$

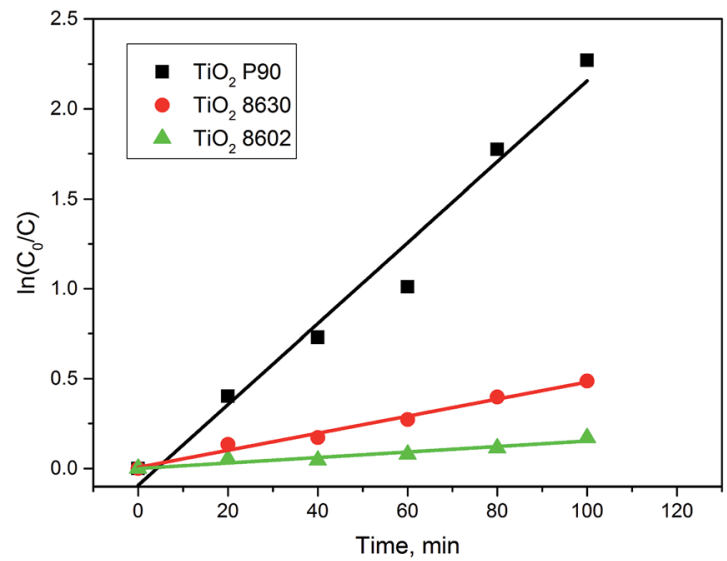

Fig. 1 Rhodamine $\mathrm{B}$ degradation with different $\mathrm{TiO}_{2}$ nanopowders.

order: $\mathrm{TiO}_{2} \mathrm{P} 90<\mathrm{TiO}_{2}$ Hombikat $8630<\mathrm{TiO}_{2}$ Hombikat 8602 . The average agglomerate size for $\mathrm{TiO}_{2}$ P90 was ca. $100 \mathrm{~nm}$ in DMF and $200 \mathrm{~nm}$ in acetone.

As consequence of different compositions and properties, the three $\mathrm{TiO}_{2}$ materials interact differently with the organic dyes under UV excitation at $365 \mathrm{~nm}$. For example for the decomposition of rhodamine $\mathrm{B}, \mathrm{TiO}_{2} \mathrm{P90}$ is the most active material, followed by the Hombikat 8630 and finally by the Hombikat 8602 (Fig. 1). Photodegradation by UV excitation at $365 \mathrm{~nm}$ of rhodamine $\mathrm{B}$ in the absence of the catalyst was not observed for irradiation times up to $2 \mathrm{~h}$ (see ESI, Fig. SI- $2 \dagger$ ).

With all three types of titanium dioxide nanopowders cellulose acetate-based membranes with a composition $\mathrm{CA}: \mathrm{TiO}_{2}=10: 2$ have been prepared by phase separation from polymer solutions in DMF. Membranes with similar pore structure have been obtain in all cases; however differences in the agglomeration degree of the $\mathrm{TiO}_{2}$ dopant in the porous membranes have been observed (see ESI, Fig. SI- $3 \dagger$ ). As expected, the membranes have accordingly different catalytic properties (see ESI, Fig. SI-4 $\dagger$ ); however it is very interesting to observe that by embedment in the cellulose acetate matrix, the
$\mathrm{TiO}_{2}$ Hombikat 8602 loses its catalytic activity to the smallest extent (see ESI, Fig. SI-5†).

Because the catalytic results are more promising for the membranes obtained using $\mathrm{TiO}_{2}$ 90, the further investigations have been performed using this catalyst.

By dissolution of CA in the $\mathrm{TiO}_{2} \mathrm{P} 90$ dispersions in DMF and acetone, casting solutions with different viscosities have been obtained: $1.100 \mathrm{cP}$ in DMF and $500 \mathrm{cP}$ in acetone. The rate of the demixing process affects the morphology of the formed membrane. This can be also observed in the different morphologies of the $\mathrm{CA}: \mathrm{TiO}_{2}$ membranes formed from acetone and DMF polymer solutions and using water as nonsolvent (Fig. 2). When DMF is used as solvent, instantaneous demixing takes place leading to the formation of a membrane with macrovoids. ${ }^{32}$ When acetone solutions are used, due to high volatility of acetone and fast water diffusivity, delayed demixing occurs and membranes with sponge-like structure are formed. ${ }^{32}$

As observed from the Fig. 2, both membranes exhibit catalytic activity, which, however, is lower when compared with the same mass of pure catalyst. The main reason is the loss of active surface of the catalyst by embedment in the polymer matrix. The catalytic activity of the membrane prepared from DMF solution is three times higher (Table 1) as compared to the equivalent membrane prepared from acetone solution. This reduced catalytic activity of the membrane prepared from acetone based solution may be connected with higher agglomeration of the $\mathrm{TiO}_{2}$ in acetone (see ESI, Fig. SI- $1 \dagger$ ), but also with the lower porosity of the membrane surfaces (see ESI, Fig. SI-6†). Additionally, the membrane prepared from acetone solution is slightly less hydrophilic than the equivalent one prepared from DMF solution (see ESI, Fig. SI-7 $\dagger$ ).

Because the catalytic results are more promising for the membranes obtained by phase separation from polymer solutions in DMF, the further investigations have been performed on this type of membranes.

The influence of the $\mathrm{TiO}_{2}$ content on the phase separation process and on the resulting membrane characteristics was studied in detail. No significant change in the outcome of the phase separation process was observed with the increase of the nanocatalyst content in the membrane; however a slightly larger

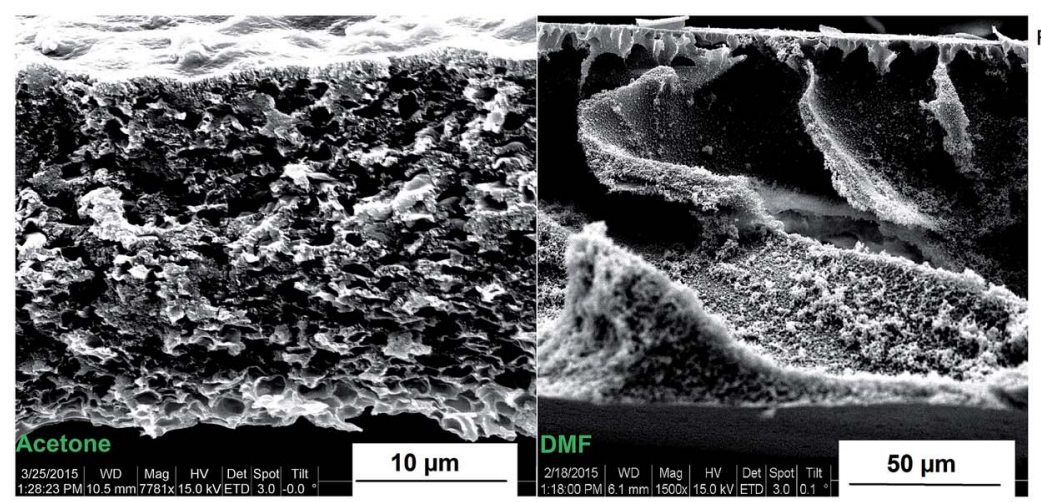

Rhodamin $\mathrm{B}\left(5 \times 10^{-5} \mathrm{~mol} / \mathrm{l}\right.$ in water $)$ degradation by UV excitation at $365 \mathrm{~nm}$

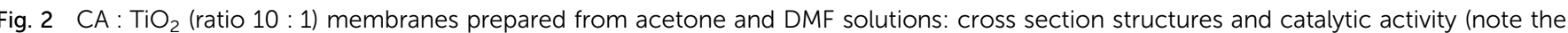
different magnifications in the two SEM micrographs). 
Table 1 Rate constant $k$ for the catalytic degradation of rhodamine $B$ $\left(5 \times 10^{-5} \mathrm{~mol} \mathrm{~L}^{-1}\right.$ in water) with different catalytic materials

\begin{tabular}{|c|c|c|}
\hline Sample & Deacetylation & $k\left[\min ^{-1}\right]$ \\
\hline $\mathrm{TiO}_{2} \mathrm{P} 90$ & - & $0.0225 \pm 0.0018$ \\
\hline $\mathrm{TiO}_{2} 8630$ & - & $0.0048 \pm 0.0003$ \\
\hline $\mathrm{TiO}_{2} 8602$ & - & $0.0015 \pm 0.0002$ \\
\hline $\mathrm{TiO}_{2} \mathrm{P} 90$ & $0.2 \mathrm{~N} \mathrm{KOH}$ in $\mathrm{H}_{2} \mathrm{O}$ & $0.0020 \pm 0.0005$ \\
\hline $\begin{array}{l}\mathrm{CA}: \mathrm{TiO}_{2}=10: 1 \\
\text { (acetone) }\end{array}$ & - & $0.0022 \pm 0.0005$ \\
\hline $\begin{array}{l}\mathrm{CA}: \mathrm{TiO}_{2}=10: 1 \\
(\mathrm{DMF})\end{array}$ & - & $0.0079 \pm 0.0004$ \\
\hline $\begin{array}{l}\mathrm{CA}: \mathrm{TiO}_{2}=10: 1.5 \\
(\mathrm{DMF})\end{array}$ & - & $0.0168 \pm 0.0004$ \\
\hline $\begin{array}{l}\mathrm{CA}: \mathrm{TiO}_{2}=10: 2 \\
(\mathrm{DMF})\end{array}$ & - & $0.0140 \pm 0.0002$ \\
\hline $\begin{array}{l}\mathrm{CA}: \mathrm{TiO}_{2}=10: 1 \\
(\mathrm{DMF})\end{array}$ & $0.5 \mathrm{~N} \mathrm{KOH}$ in $\mathrm{H}_{2} \mathrm{O}: \mathrm{EtOH}$ & Near detection limit \\
\hline $\begin{array}{l}\mathrm{CA}: \mathrm{TiO}_{2}=10: 1 \\
(\mathrm{DMF})\end{array}$ & $\begin{array}{l}\text { Direct phase separation in } \\
0.25 \mathrm{~N} \mathrm{KOH} \text { in } \mathrm{H}_{2} \mathrm{O}: \text { EtOH }\end{array}$ & Near detection limit \\
\hline $\begin{array}{l}\mathrm{CA}: \mathrm{TiO}_{2}=10: 1 \\
(\mathrm{DMF})\end{array}$ & $\begin{array}{l}\text { Direct phase separation in } \\
0.2 \mathrm{~N} \mathrm{KOH} \text { in } \mathrm{H}_{2} \mathrm{O}\end{array}$ & Near detection limit \\
\hline
\end{tabular}

density of catalyst agglomerates within the polymer and a slight increase in the agglomerate size was observed at higher concentrations of $\mathrm{TiO}_{2}$ (Fig. 3). This observation is in good agreement with the results of the DLS investigations performed on dispersions with different contents of $\mathrm{TiO}_{2}$ in $\mathrm{DMF}$ where a pronounced increase in average agglomerate size from $c a$. $100 \mathrm{~nm}$ at $1 \%$ to a main size in the range of $300 \mathrm{~nm}$ and a very broad distribution had been observed (see ESI, Fig. SI-8 $\dagger$ ). The general tendency is that the agglomerate sizes are increasing with the increase of the nanopowder concentration. Additionally, with the increase of the nanoparticle fraction in the nanocomposite a slight decrease in the hydrophilicity of the membrane was observed (see ESI, Fig. SI-9†).

All membranes with different $\mathrm{TiO}_{2}$ contents have shown good catalytic activity. At the increase of the $\mathrm{TiO}_{2}$ concentration from $10 \mathrm{wt} \%$ to $15 \mathrm{wt} \%$ the catalytic activity doubled. At the further increase of the $\mathrm{TiO}_{2}$ concentration to $20 \mathrm{wt} \%$ a slight decrease of the catalytic activity in comparison to the membrane with 15 wt $\% \mathrm{TiO}_{2}$ was observed (Fig. 4 and Table 1).

When evaluating the catalytic activity of the $\mathrm{CA}: \mathrm{TiO}_{2}$ porous nanocomposites, the following aspects should be taken into consideration: by increasing the amount of $\mathrm{TiO}_{2}$ in the material, the amount of catalytically active species in the composite increases; therefore the resulted membrane is more catalytically active. However, too high $\mathrm{TiO}_{2}$ concentration will lead to strong agglomeration of the nanopowder in the composite, having as consequence the reduction of the available catalytically active surface. This effect is much more pronounced than the possible negative effect generated by the slight decrease of hydrophilicity. Therefore, for each type of membrane, studies are necessary in order to identify the optimal amount of catalytically active material which should be embedded in the membrane. Here, the loading of $15 \% \mathrm{TiO}_{2}$ relative to cellulose acetate seemed to be close to the optimum.

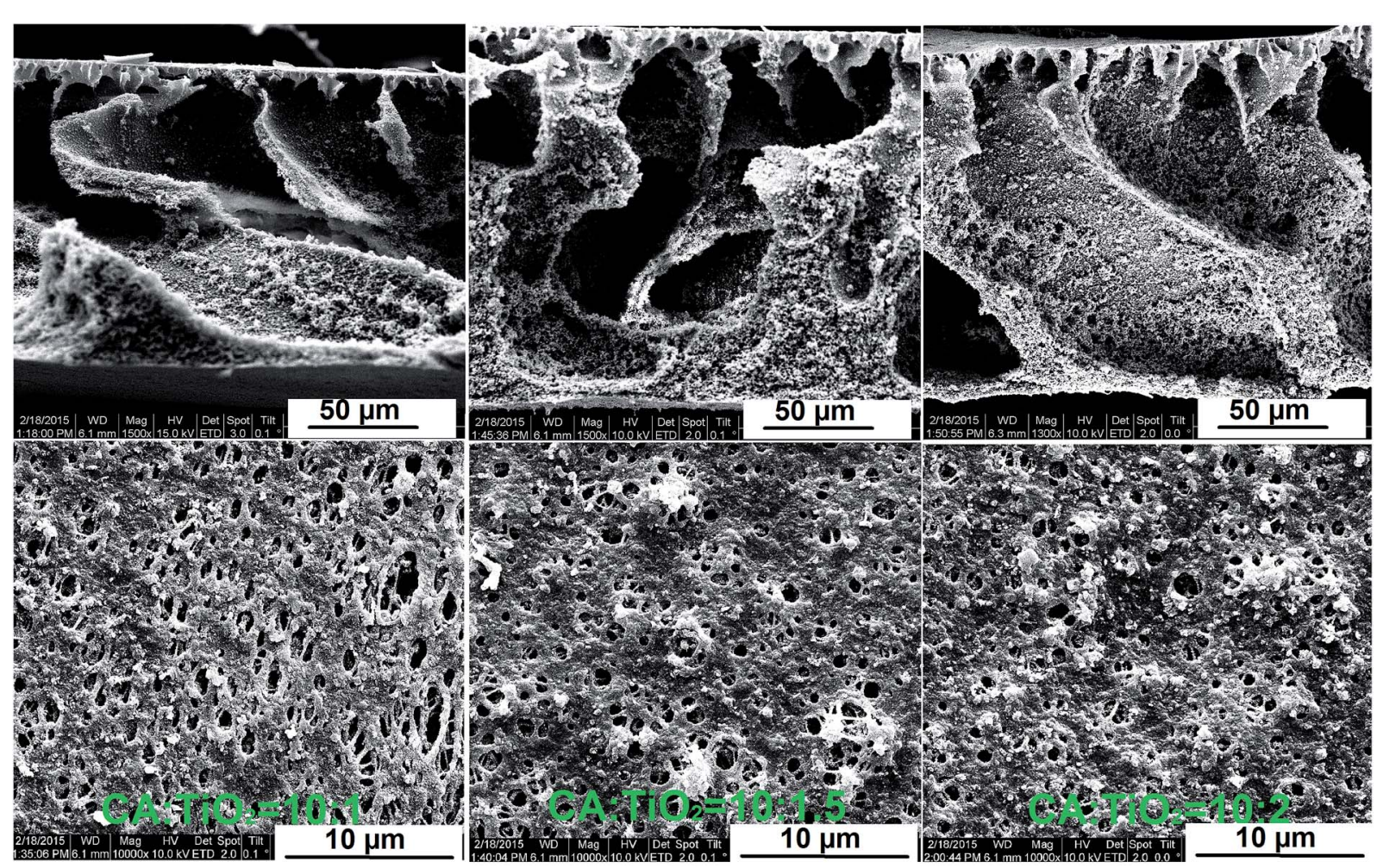

Fig. 3 Scanning electron microscopy images (cross section and glass surface) of $\mathrm{CA}$ : $\mathrm{TiO}_{2}$ membranes with different $\mathrm{TiO}_{2}$ concentrations. 
Rhodamine $B\left(5 \times 10^{-5} \mathrm{~mol} / \mathrm{l}\right.$ in water $)$ degradation by UV excitation at $365 \mathrm{~nm}$

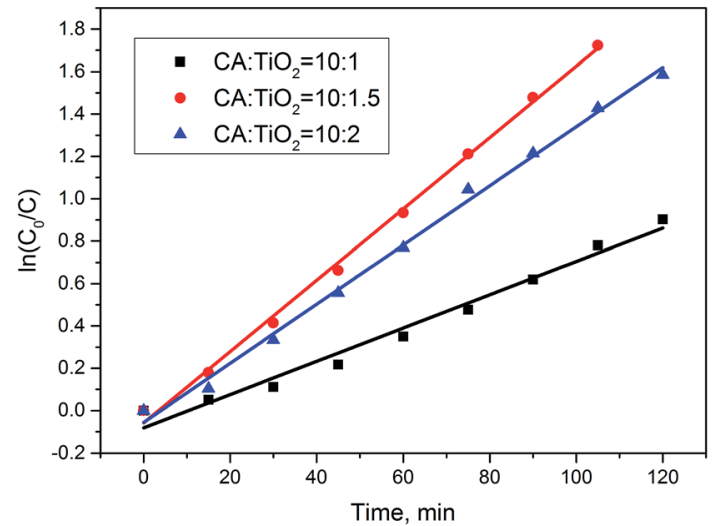

Fig. 4 Rhodamine $\mathrm{B}$ degradation with $\mathrm{CA}$ : $\mathrm{TiO}_{2}$ membranes (dried nanocomposite) having different $\mathrm{TiO}_{2}$ content (same amount of composite).

Different $\mathrm{TiO}_{2}$ doped cellulose membranes have been prepared by deacetylation of the corresponding cellulose acetate membranes, either by deacetylation post precipitation (Fig. 5A), or by simultaneous deacetylation and precipitation (Fig. 5B and C). Depending on the chosen method of deacetylation, membranes with different porous structure have been obtained (Fig. 5). The success of the deacetylation process was assessed by FT-IR spectroscopy. In all cases it was observed that the peaks at $\sim 1740 \mathrm{~cm}^{-1}$ corresponding to the $\mathrm{C}=\mathrm{O}$ stretch vibration and $\sim 1220 \mathrm{~cm}^{-1}$ corresponding to the $\mathrm{C}-\mathrm{O}$ vibration, both for the ester groups, are disappearing from the composite spectrum (see ESI, Fig. SI-10†). In the two step process, the changes in the original membrane structure after the cellulose regeneration by alkaline treatment have been attributed by Park and collaborators to the rearrangement of the polymer chains during the deacetylation and to a change of the solid state structure of CA toward crystalline phases of cellulose. ${ }^{40}$ In the one step process, the polymer precipitation and its structural change and organization take place simultaneously.

Regardless of the method of deacetylation applied, all the formed $\mathrm{TiO}_{2}$ doped cellulose membranes had considerably lower catalytic activity when compared with the cellulose acetate based intermediates (Fig. 6 and Table 1).

Literature mentions that the reaction of $\mathrm{TiO}_{2}$ with $\mathrm{KOH}$ leads to poisoning of Lewis acid sites and surface hydroxyl groups. ${ }^{\mathbf{4 1}}$ In order to prove this hypothesis, pure $\mathrm{TiO}_{2} \mathrm{P90}$ was treated with a $0.2 \mathrm{~N} \mathrm{KOH}$ solution, then separated by centrifugation, thoroughly washed with distilled water and finally dried. The catalytic activity of the $\mathrm{KOH}$ treated $\mathrm{TiO}_{2}$ powder was tested in analogous manner as for the native material. As in the case of the deacetylated membranes a decrease of the catalytic activity of the material was observed, in line with the poisoning of the catalyst (Fig. SI-11†). Partially, this decrease of catalytic activity may also be connected with the aggregation of the $\mathrm{TiO}_{2}$ nanoparticles after the alkaline treatment.
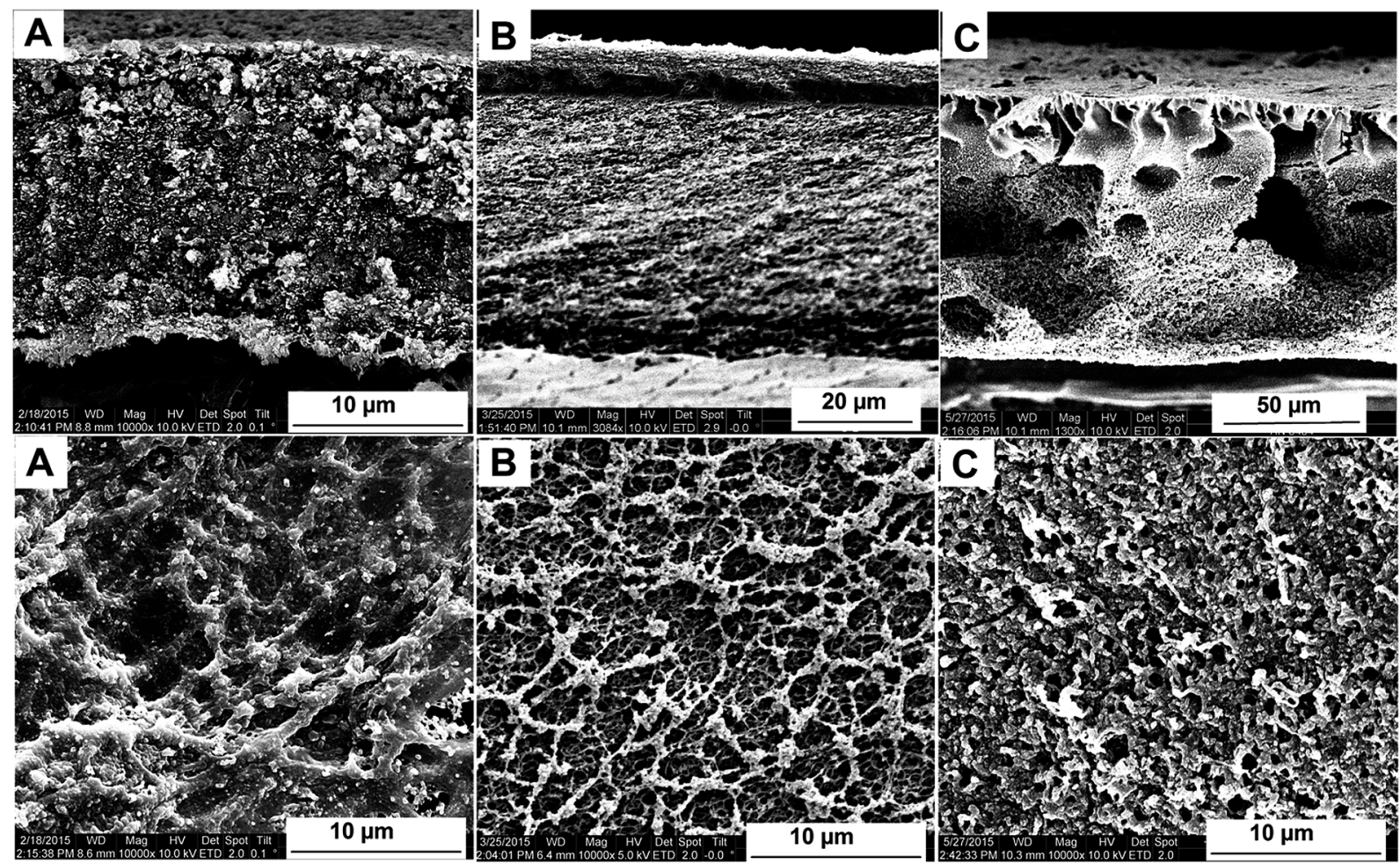

Fig. 5 Scanning electron microscopy images (cross section and glass surface) of cellulose nanocomposite (from CA:TiO $2=10: 1)$ membranes: (A) deacetylated post phase separation in $0.5 \mathrm{~N} \mathrm{KOH}$ in $\mathrm{H}_{2} \mathrm{O}$ : EtOH; (B) direct phase separation in $0.25 \mathrm{~N} \mathrm{KOH}$ in $\mathrm{H}_{2} \mathrm{O}$ : EtOH; $(C)$ direct phase separation in $0.2 \mathrm{~N} \mathrm{KOH}$ in $\mathrm{H}_{2} \mathrm{O}$. 
Rhodamine $B\left(5 \times 10^{-5} \mathrm{~mol} / /\right.$ in water $)$ degradation by UV excitation at $365 \mathrm{~nm}$

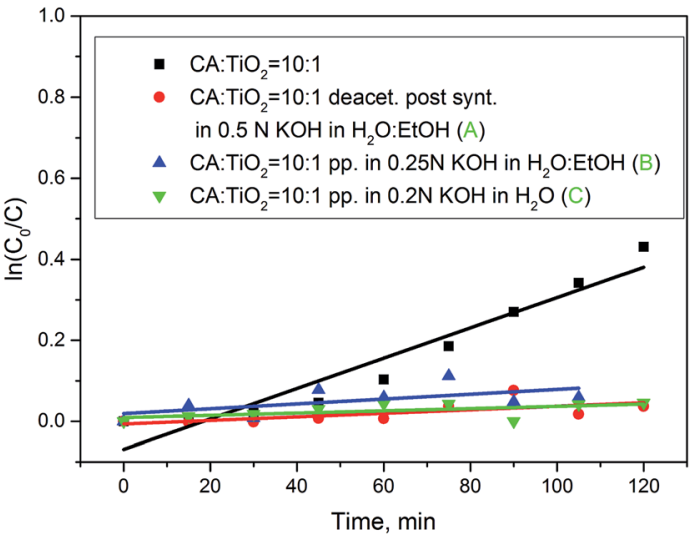

Fig. 6 Catalytic activity of cellulose nanocomposite (from $\mathrm{CA}: \mathrm{TiO}_{2}=$ 10 : 1) membranes: (A) deacetylated post phase separation in $0.5 \mathrm{~N}$ $\mathrm{KOH}$ in $\mathrm{H}_{2} \mathrm{O}$ : EtOH; (B) direct phase separation in $0.25 \mathrm{~N} \mathrm{KOH}$ in $\mathrm{H}_{2} \mathrm{O}$ : EtOH; (C) direct phase separation in $0.2 \mathrm{~N} \mathrm{KOH}$ in $\mathrm{H}_{2} \mathrm{O}$; precursor membrane for comparison.

As a next step, an optimization of the deacetylation process was performed with the aim to establish conditions where the exposure of the nanocomposite to the $\mathrm{KOH}$ solution is minimized or to find a viable route which will allow catalyst "reactivation" after the completion of the deacetylation step (e.g. treatment of the membrane with a diluted acid).

Firstly, it was investigated which is the minimal exposure time to $\mathrm{KOH}$ solutions of different concentrations necessary for a complete deacetylation of the cellulose acetate intermediate. Therefore cellulose acetate membranes were exposed to the desired alkaline solution for fixed amounts of time, then thoroughly washed and finally dried. The required time for complete deacetylation was ca. $260 \mathrm{~min}$ at the immersion in $0.05 \mathrm{~N}$ aqueous $\mathrm{KOH}$ and $c a .90 \mathrm{~min}$ at the immersion in $0.1 \mathrm{~N}$ aqueous $\mathrm{KOH}$ solutions (Fig. 7; see also ESI, Fig. SI-12†).

Regardless of the concentration of alkaline solution and deacetylation time, all regenerated cellulose membranes have shown much lower catalytic activity than their cellulose acetate precursor. The "Test 1" has, however, clearly shown that even though the membranes are considerably less active after deacetylation, the photocatalytic activity is not

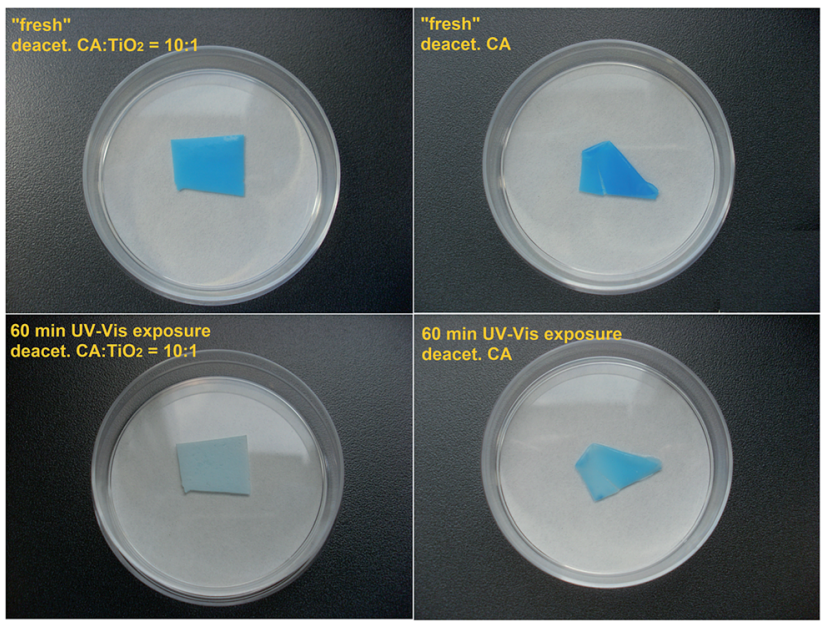

Fig. 8 Photocatalytic degradation of methylene blue adsorbed on cellulose nanocomposite obtained by deacetylation of an $\mathrm{CA}: \mathrm{TiO}_{2}=$ 10:1 membrane (left) and adsorbed on cellulose obtained from deacetylation of a CA membrane (right).

completely lost. A slow decomposition of the organic dye adsorbed in the membrane under UV-Vis exposure (sunlight) has been observed, as confirmed by exemplary data shown in Fig. 8 left. In order to prove that it is not a case of dye bleach, the same test was performed on deacetylated cellulose without $\mathrm{TiO}_{2}$. In the absence of the catalyst, decoloration upon UV-Vis exposure (sunlight) was very much less pronounced (Fig. 8 right).

Attempts toward reactivation of activity of cellulose nanocomposites with dilute aqueous $\mathrm{HCl}$ had not been successful. Different other post-deacetylation treatments, aiming the reactivation of the $\mathrm{TiO}_{2}$, will be the objective of planned future work.

\section{Conclusions}

In the present work, the potential offered by the two step and the one step preparation methods of $\mathrm{TiO}_{2}$ doped porous cellulose nanocomposites, starting with nanoparticle dispersions in cellulose acetate solutions in organic solvents, had been
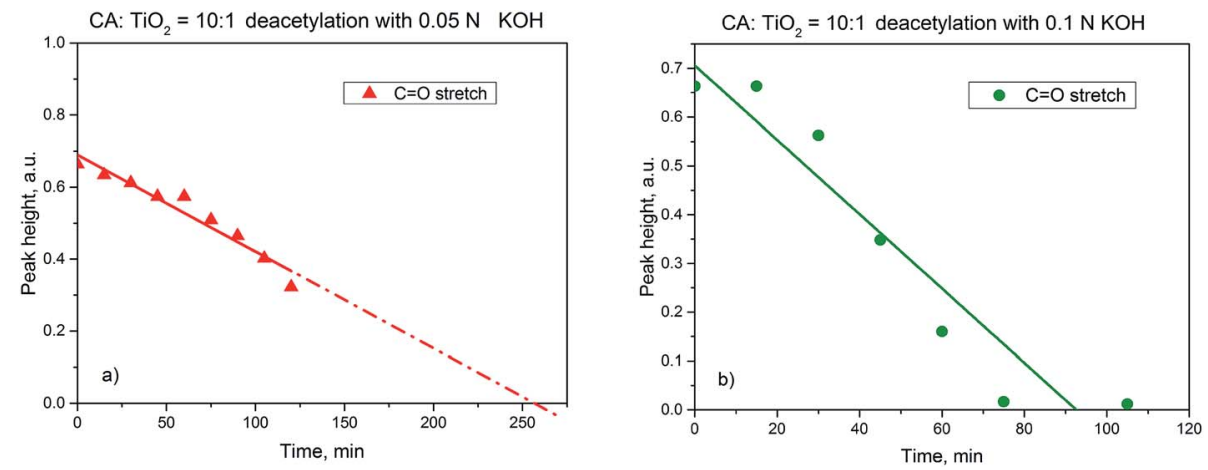

Fig. 7 Height of $\mathrm{C}=\mathrm{O}$ stretch peak in the membranes FT-IR spectrum vs. time for deacetylation in $0.05 \mathrm{~N}$ aqueous $\mathrm{KOH}$ (a) and $0.1 \mathrm{~N}$ aqueous $\mathrm{KOH}(\mathrm{b})$ solutions. 
analyzed in detail. $\mathrm{TiO}_{2}$ doped porous cellulose acetate nanocomposite membranes have been prepared by phase separation from polymer solutions in organic solvents using water as precipitation medium. The obtained nanocomposite membranes can directly be used as catalytically active materials or can serve in the second step as precursor for the preparation of $\mathrm{TiO}_{2}$ doped porous cellulose membranes. The cellulose regeneration from cellulose acetate based materials was simply realized by alkaline treatment. Three types of catalytically active commercial titanium dioxide nanopowders have been investigated and it was observed an increase of the photocatalytic activity for degradation of organic dyes in the following order: Hombikat $8602<$ Hombikat $8630<$ P90. A similar increase of the catalytic activity was also obtained for the corresponding cellulose acetate based membranes. As expected, by simply changing the cellulose acetate solvent it was possible to change the membrane porous structure. The addition of inorganic nanoparticles did not have a considerable influence of the porous membrane formation during the phase separation process. It was observed that the membrane prepared from DMF solution has considerably better catalytic activity than the corresponding membrane obtained from acetone solution. By increasing the amount of the $\mathrm{TiO}_{2}$ in the $\mathrm{CA}: \mathrm{TiO}_{2}$ nanocomposite an increase of the photocatalytic activity of the membrane was observed until a certain value. Increase of $\mathrm{TiO}_{2}$ content beyond that level lead to lower catalytic activity. Therefore the optimal doping amount for each type of membranes should be determined. Sequential deacetylation after phase separation process leads to a partial collapsing of the pores in the resulted $\mathrm{TiO}_{2}$ doped cellulose-based membranes. Similar structures as the ones obtained for the cellulose acetate intermediates can be also obtained for the cellulose membranes when the deacetylation takes place simultaneously with the phase separation of films of cellulose acetate solutions. By increasing the alkali concentration, the rate of the deacetylation process can be increased. Regardless of the route used for the cellulose regeneration, a decrease of catalytic activity of the resulted $\mathrm{TiO}_{2}$ doped nanocomposite membranes was observed, apparently due to $\mathrm{TiO}_{2}$ poisoning. The huge potential of this approach is given by relatively cheap materials which are available at larger scale (good potential for up-scaling) as well as by the very large number of possibilities to influence the membrane structure formation for different targeted applications due to wide range of solvents, many possible compositions of the coagulation bath and various possible compositions of the deacetylation bath. Studies concerning the optimization of the deacetylation process and about the "reactivation" of the catalyst in the cellulose-based composites will make the objective of future studies. Additionally, the $\mathrm{TiO}_{2}$ doped porous cellulose will be used as precursor for the preparation of catalytically active carbon based nanocomposites.

\section{Acknowledgements}

We gratefully acknowledge the collaboration with Mr Smail Boukercha (SEM characterization) at the University of DuisburgEssen.

\section{References}

1 J. Langley and D. Holroyd, US. Pat., 4913 775, 1990.

2 R. C. Law, Macromol. Symp., 2004, 208, 255.

3 D. Klemm, B. Heublein, H. P. Fink and A. Bohn, Angew. Chem., Int. Ed., 2005, 44, 3358.

4 H. Ma, C. Burger, B. S. Hsiao and B. Chu, J. Mater. Chem., 2011, 21, 7507.

5 G. M. Geise, H. S. Lee, D. J. Miller, B. D. Freeman, J. E. McGrath and D. R. Paul, J. Polym. Sci., Part B: Polym. Phys., 2010, 48, 1685.

6 N. Hoenich, BioResources, 2006, 1, 270.

7 Q. Wang, A. Fu, H. Li, J. Liu, P. Guo, X. S. Zhao and L. H. Xia, Carbohydr. Polym., 2014, 111, 393.

8 S. Mahmoudian, M. U. Wahit, A. F. Ismail and A. A. Yussuf, Carbohydr. Polym., 2012, 88, 1251.

9 H. Song and L. Zheng, Cellulose, 2013, 20, 1737.

10 S. K. Mahadeva and J. Kim, Sens. Actuators, B, 2011, 157, 177. 11 D. Fragouli, I. S. Bayer, R. Di Corato, R. Brescia, G. Bertoni, C. Innocenti, D. Gatteschi, T. Pellegrino, R. Cingolani and A. Athanassiou, J. Mater. Chem., 2012, 22, 1662.

12 M. Ul-Islam, W. A. Khattak, M. W. Ullah, S. Khan and J. K. Park, Cellulose, 2014, 21, 433.

13 S. M. Li, L. H. Fu, M. G. Ma, J. F. Zhu, R. C. Sun and F. Xu, Biomass Bioenergy, 2012, 47, 516.

14 S. M. Li, Y. Y. Dong, M. G. Ma, L. H. Fu, R. C. Sun and F. Xu, Carbohydr. Polym., 2013, 96, 15.

15 J. Zheng, S. Liu, J. Cai and L. Zhang, J. Phys. Chem. C, 2010, 114, 7806.

16 K. Hashimoto, H. Irie and A. Fujishima, Jpn. J. Appl. Phys., 2005, 44, 8269.

17 G. K. Mor, O. K. Varghese, M. Paulose, K. Shankar and C. A. Grimes, Sol. Energy Mater. Sol. Cells, 2006, 90, 2011.

18 G. Pfaff and P. Reynders, Chem. Rev., 1999, 99, 1963.

19 G. X. Shen, Y. C. Chen and C. J. Lin, Thin Solid Films, 2005, 489, 130.

20 C. Euvananont, C. Junin, K. Impor, P. Limthongkul and C. Thanachayanont, Ceram. Interfaces, 2008, 34, 1067.

21 Y. C. Zhang, M. Yang, G. Zhang and D. D. Dionysiou, Appl. Catal., B, 2013, 142-143, 249.

22 A. Turki, C. Guillard, F. Dappozze, Z. Ksibi, G. Berhault and H. Kochkar, Appl. Catal., B, 2015, 163, 404.

23 M. Pelaez, N. T. Nolan, S. C. Pillai, M. K. Seery, P. Falaras, A. G. Kontos, P. S. M. Dunlop, J. W. J. Hamilton, J. A. Byrne, K. O'Shea, M. H. Entezari and D. D. Dionysiou, Appl. Catal., B, 2012, 125, 331.

24 T. Luttrell, S. Halpegamage, J. Tao, A. Kramer, E. Sutter and M. Batzill, Sci. Rep., 2014, 4, 4043.

25 D. O. Scanlon, C. W. Dunnill, J. Buckeridge, S. A. Shevlin, A. J. Logsdail, S. M. Woodley, C. R. A. Catlow, M. J. Powell, R. G. Palgrave, I. P. Parkin, G. W. Watson, T. W. Keal, P. Sherwood, A. Walsh and A. A. Sokol, Nat. Mater., 2013, 12, 798.

26 R. Abedini, S. M. Mousavi and A. Aminzadeh, Desalination, 2011, 277, 40.

27 G. Goncalves, P. A. A. P. Marques, R. J. B. Pinto, T. Trindade and C. P. Neto, Compos. Sci. Technol., 2009, 69, 1051. 
28 W. A. Daoud, J. H. Xin and Y. H. Zhang, Surf. Sci., 2005, 599, 69.

29 S. M. Li, Y. Y. Dong, M. G. Ma, L. H. Fu, R. C. Sun and F. Xu, Carbohydr. Polym., 2013, 96, 15.

30 J. Zeng, S. Liu, J. Cai and L. Zhang, J. Phys. Chem. C, 2010, 114, 7806.

31 T. Zhu, Y. Lin, Y. Luo, X. Hu, W. Lin, P. Yu and C. Huang, Carbohydr. Polym., 2012, 87, 901.

32 Y. Luo, J. Xu and J. Huang, CrystEngComm, 2014, 16, 464.

33 S. D. Wang, Q. Ma, H. Liu, K. Wang, L. Z. Ling and K. Q. Zhang, RSC Adv., 2015, 5, 40521.

34 T. Liebert, ACS Symp. Ser., 2010, 1033, 3.

35 P. van der Witte, P. J. Dijkstra, J. W. A. van der Berg and J. Feijen, J. Membr. Sci., 1996, 117, 1.
36 G. R. Guillen, Y. Pan, M. Li and E. M. V. Hoek, Ind. Eng. Chem. Res., 2011, 50, 3798.

37 M. A. Mohamed, W. N. W. Salleh, J. Jaafar, A. F. Ismail, M. A. Mutalib and S. M. Jamil, Carbohydr. Polym., 2015, 133, 429.

38 M. A. Mohamed, W. N. W. Salleh, J. Jaafar, A. F. Ismail, M. A. Mutalib, N. A. A. Sani, S. E. A. M. Asri and C. S. Ong, Chem. Eng. J., 2016, 284, 202.

39 A. Wittmar, H. Thierfeld, S. Köcher and M. Ulbricht, RSC Adv., 2015, 5, 35866.

40 W. K. Son, J. H. Youk, T. S. Lee and W. H. Park, J. Polym. Sci., Part B: Polym. Phys., 2004, 42, 5.

41 B. Imelik, C. Iaccache, G. Coundrier, Y. Ben Taarit and J. C. Vedrine, Catalysis by acids and bases, Elsevier Science Publishers B.V., 1985, p. 22. 